\title{
The Impact of TRMM Data on Mesoscale Numerical Simulation of Super Typhoon Paka
}

\author{
Zhao-Xia Pu ${ }^{1,2, *}$, Wei-Kuo Tao ${ }^{2}$, Yiqin $\mathrm{Jia}^{2,3}$, Joanne Simpson ${ }^{2}$, \\ Scott A. Braun ${ }^{2}$, Jeffrey Halverson ${ }^{2,4}$, Arthur Hou ${ }^{2}$, and William Olson ${ }^{2,4}$ \\ ${ }^{\prime}$ Goddard Earth Sciences and Technology Center \\ University of Maryland, Baltimore County \\ Baltimore, Maryland \\ USA \\ ${ }^{2}$ Laboratory for Atmospheres \\ NASA/Goddard Space Flight Center \\ Greenbelt, Maryland \\ USA \\ ${ }^{3}$ Science System and Applications Inc. \\ Lanham, Maryland \\ $U S A$ \\ ${ }^{4}$ Joint Center of Earth System Technology \\ University of Maryland, Baltimore County \\ Baltimore, Maryland \\ USA
}

To be Submitted

Journal of the Meteorological Society of Japan

(February 22, 2001)

Corresponding author address: Dr. Zhao-Xia Pu, Mail Code 912, NASA/GSFC, Greenbelt, MD 20771, USA.

Email: pu@agnes.gsfc.nasa.gov 


\begin{abstract}
This paper assesses the impact of TRMM Microwave Imager (TMI) derived surface rainfall data on the numerical simulation of Super Typhoon Paka (1997). A series of mesoscale numerical simulations is conducted for simulating Super Typhoon Paka during its mature stage by using the Penn State/NCAR MM5 model with initial conditions derived from the Goddard Earth Observing System (GEOS) global analyses with and without assimilation of the TMI surface rainfall data. Simulation results clearly demonstrate that the GEOS analysis with TMI rainfall data leads to a improved MM5 simulation of Typhoon Paka in terms of its intensity and kinematical and precipitation structures, since inclusion of the rainfall data into initial and boundary condition improves the storm environmental conditions (e.g., moisture and circulation). Further improvement can also be obtained by incorporating TMI data with mesoscale bogus vortex information into the initial conditions.
\end{abstract}




\section{Introduction}

It has long been recognized that the accurate rainfall measurement over the tropical region is one of the most important factors for tropical weather and climate studies. Recent numerical studies have also demonstrated that the inclusion of the rainfall data into numerical model would impact on the numerical weather forecasts (e.g., Krishnamurti et al. 1993; Zupanski and Mesinger 1993). However, the accurate measurement of the spatial and temporal variation of tropical rainfall around the globe remains one of the critical unsolved problems of meteorology until the lunch of recent Tropical Rainfall Measuring Mission (TRMM). During TRMM's six-year mission, its broad sampling footprint between $35^{\circ} \mathrm{N}$ and $35^{\circ} \mathrm{S}$ is providing the first detailed and comprehensive dataset on the four-dimensional distribution of rainfall and latent heating over vastly under sampled oceanic and tropical continental regions. TRMM offers a unique opportunity to improve understanding of tropical meteorology and also offers great chance to evaluate the impact of rainfall data on the tropical weather forecast.

Among a lot of the tropical weather events, typhoon is one of the great challenges for numerical weather prediction because the conventional observations are usually sparse over the tropical ocean. Therefore, it is urgent to incorporate the satellite data into numerical weather model. This study assesses the impact of TRMM Microwave Imager (TMI) derived surface rainfall data on the numerical simulation of Super Typhoon Paka.

According to the early study, Super Typhoon Paka was one event frequently sampled by TRMM in 1997 (Rodgers et al. 2000). In this study, a set of mesoscale numerical simulations is performed for Paka during its mature stage with the initial conditions generated by two different global analyses from the Goddard Earth Observing 
System (GEOS): one with and one without TRMM rainfall data. The Penn State University / National Center for Atmospheric Research (PSU/NCAR) nonhydrostatic regional Mesoscale Model version 5 (MM5) is used to conduct the mesoscale simulations. Details of the numerical results will demonstrate the impacts of the TRMM data on the simulations of Paka, and identify how these impacts are associated with the rainfall data.

Since bogus vortices are often necessary for improving forecasts of mature hurricanes (Kurihara et al. 1993; Zou and Xiao 2000; Pu and Braun 2001), as part of this evaluation, additional numerical experiments are performed by introducing bogus vortices generated by four-dimensional variational data assimilation (4-D VAR) using the MM5 adjoint system. In one of the experiments, the bogus vortex is incorporated into the mesoscale initial conditions with the TMI data.

A brief overview of Super Typhoon Paka is given in section 2, and a description of the TMI surface rainfall data and GEOS data assimilation are addressed in Section 3. The mesoscale model and experimental design are described in section 4 , and simulation results are given in section 5 . A brief summary and discussion are provided in section 6 .

\section{A brief overview of Super Typhoon Paka}

Typhoon Paka formed during the first week of December 1997 and underwent three periods of rapid intensification over the following two weeks. Rodgers et al. (2000) analyzed the detail structural features of Typhoon Paka during its life time using the TRMM and the Defense Meteorological Satellite Program's special sensor microwave/imager (SSM/I) satellite observations. Figure 1 shows Paka's intensity and 
$\mathrm{SSM} / \mathrm{I}$ and TMI derived mean total inner-core (within $111 \mathrm{~km}$ of the center) rain rates for the period between 9 and 21 Dec 1997. During the earlier periods, which started early on December 10, Paka's maximum wind speed increased from 23 to $60 \mathrm{~ms}^{-1}$ over a 48-hr period with Paka becoming a mature category 3 typhoon on December 11. Later, Paka continued to intensify on the following days. By December 18, during the last rapid deepening period, Paka became a super typhoon with a maximum wind speed of about 80 $\mathrm{ms}^{-1}$. In order to test the impact of the TMI rainfall data on the forecast of Paka during its mature stage, 0000UTC 12 December 1997 is taken as the initial time for the numerical simulations in this study.

\section{Surface rainfall data and GEOS rainfall assimilations}

\subsection{TMI Surface Rainfall data}

The surface rainfall information is retrieved from the TMI microwave radiances. The basis of the rainfall retrieval method is the "Bayesian" technique described in Kummerow et al. (1996) and Olson et al. (1996, 1999). A detailed description of the retrieval method utilized in the present study can be found in Olson et al. (1999). The retrieval method is supported by a large database of hydrometer profiles that are generated from three-dimensional numerical cloud-resolving model simulations (Tao and Simpson 1993; Wang et al. 2001). The three-dimensional model fields are used to simulate the microwave radiances at the TMI frequencies/polarizations using an Eddington radiative transfer method. Given a set of actual TMI observed radiances, the retrieved hydrometeor profile is calculated as a weighted mean of the model profiles: 
only those model profiles associated with radiances similar to the observed radiances are designated significant weights.

\subsection{GEOS analysis}

The 6-h averaged surface rainfall estimates derived from the TMI are assimilated into the global analysis using a version of GEOS data assimilation system (see Hou et al. 2000). The analysis system uses the second generation of the GEOS GCM (GEOS-2 GCM, version 5.9) and version 1.5 of the optimal interpolation (OI) analysis scheme. The prognostic variables are potential temperature, specific humidity, surface pressure, and winds in the zonal and meridional directions computed at the resolution of $2^{\circ}$ latitude, $2.5^{\circ}$ longitude, and $46 \sigma$ levels from the surface to $4.0 \mathrm{hPa}$. A unique feature of the GEOS data assimilation system is that it uses the "incremental analysis update" (IAU) procedure of Bloom et al. (1996) to assimilate the rainfall and other observed data. The GEOS assimilation is a time-continuous model integration with a gradual insertion of IAU " tendencies" into prognostic variables updated from rainfall and other observations every 6-h. The system eliminates the general spinup problem in rainfall data assimilation. For rainfall data assimilation, Hou et al (2000) used a general procedure that minimizes the least-square differences between time averaged TMI observations and rain rates generated by a column model averaged over a 6 - $\mathrm{h}$ analysis window. The column model is a column version of the GEOS GCM with full model physics, with advection terms as " model forcing" along with the conventional IAU tendencies from a preliminary 6-h assimilation. The control variables are "tendency correction" of moisture and temperature. 


\section{Numerical model and experimental design}

\subsection{MM5 model}

The PSU/NCAR MM5 model is used in this study to conduct numerical simulations of Paka. The MM5 is a limited-area, non-hydrostatic primitive equation model with multiple options for various physical parameterization schemes. The model employs a terrain-following $\sigma$ vertical coordinate, where $\sigma$ is defined as $\sigma=\left(p-p_{\text {top }}\right) /\left(p_{\text {sfc }}-p_{\text {top }}\right), p$ is pressure, and $p_{\text {sfc }}$ and $p_{\text {top }}$ are the pressures at the surface and model top, respectively. Physics options used for this study include the Betts-Miller cumulus parameterization, the Goddard cloud microphysics scheme (Tao and Simpson, 1993), the Blackadar high-resolution planetary boundary layer parameterization scheme (Zhang and Anthes 1982), and the cloud atmospheric radiation scheme (Dudhia 1993). The land surface temperature is predicted using surface energy budget equations as described in Grell et al. (1995). For a more detailed description of MM5, the reader is referred to Dudhia (1993) and Grell et al. (1995).

\subsection{Experimental design}

A two-way interactive, four-level nested grid technique, is employed to achieve the multi-scale simulation. Figure 2 shows the four model domains used and Table 1 provides specifications for each domain. The outer domains A and B (135 km and $45 \mathrm{~km}$ horizontal grid spacing) are fixed and are designed to simulate the synoptic-scale and mesoscale environment in which the system evolves. The sizes of the domains are chosen sufficiently large to minimize the influence of the lateral boundary conditions. The finer domains $\mathrm{C}$ and $\mathrm{D}$ (15 km and $5 \mathrm{~km}$ grid spacing) are used to simulate the detailed 
hurricane-scale flows. The finest domain $\mathrm{D}$ is started at $24 \mathrm{~h}$ into the simulation and is frequently moved with storm center (e.g., $\mathrm{D}_{1}$ to $\mathrm{D}_{2}$ ) during the next $36 \mathrm{~h}$ simulation. The model vertical structure is comprised of $27 \sigma$ levels with the top of the model set at a pressure of $50 \mathrm{hPa}$. The $\sigma$ levels are placed at values of $1.0,0.99,0.98,0.96,0.93,0.89$, and then decrease to 0.01 at an interval 0.04 . For numerical simulations, model physics options are the same for the calculations in all above model domains except there is no cumulus parameterization scheme is included for the calculations in the finest domain (domain D, $5 \mathrm{~km}$ grid spacing).

\subsection{Model initialization with GEOS analysis}

For the experiments, the initial conditions for the $135-\mathrm{km}$ and $45-\mathrm{km}$ domains (domains $\mathrm{A}$ and $\mathrm{B}$ ) are derived from 12-h GEOS analyses. In order to examine the impact of TMI data on the storm forecast, two experiments (GEOSO and GEOSTRMM, see Table 2) are conducted with initial conditions generated by two different sets of largescale analyses from the GEOS: a control GEOS analysis data set that does not include TMI rainfall data (GEOSO) and a second analysis data set that does (GEOSTRMM). For initialization of grids $\mathrm{A}$ and $\mathrm{B}$, the GEOS analysis (without and with the TMI data) fields, including potential temperature, specific humidity, surface pressure, and winds in the zonal and meridional with the horizontal resolution of $2^{\circ}$ latitude and $2.5^{\circ}$ longitude are interpolated horizontally to the meoscale model grid points. Following the MM5's pre-processing procedure, these interpolated analyses are refined by adding information from standard twice-daily rawinsondes and 3-h surface and buoy reports using a Barnes objective analysis technique (Manning and Haagenson, 1992). Final analyses are then 
interpolated to the model $\sigma$ levels. Then, the $15-\mathrm{km}$ domain (domain $\mathrm{C}$ ) is initialized by interpolation (see Grell et al. 1995) of all prognostic variables from the 45-km domain using a monotonic interpolation scheme based upon Smolarkiewicz and Grell (1992). Domain $\mathrm{D}$ is started at $24 \mathrm{~h}$ into the forecast and is initialized by interpolation of all variables from the $15-\mathrm{km}$ domain. All figures in this paper present results from $15-\mathrm{km}$ and 5-km grids.

Figure 3 shows the MM5 initial conditions derived from the GEOS analysis without and with assimilation of TMI data (Fig.3 a and b) in a subset of the 15-km domain for fields of sea-level pressure (SLP), wind vectors and divergence at $850 \mathrm{hPa}$ at 0000UTC 12 December 1997. At the time, Paka was a mature category 3 typhoon, but the figures show only weak low pressure system with a broad wind speed maximum to the north and east of the circulation center. With assimilation of the TMI rainfall data (Fig.3b), only slight differences are found in the SLP, compared with the case without TMI data, with the low near $7^{\circ} \mathrm{N}, 167^{\circ} \mathrm{E}$ being about $0.8 \mathrm{hPa}$ deeper. However, The center of the low pressure is shifted southward into the confluence circulation (Fig. $3 \mathrm{~b}$ and c), and the significant differences appear in the wind field with increases of wind speed (about $10 \mathrm{~ms}^{-1}$ ) in the western side and southern side of the confluence center near the SLP minimum and therefore the confluence becomes even stronger (Fig.3c). As shown in the Figure $3 \mathrm{c}$, the low level divergences are decreased after insertion of TMI data into the initial condition.

Greater differences are observed in the upper level divergences and humidity fields. Figure 4 shows the divergence field at $100 \mathrm{hPa}$ and the averaged relative humidity between $500 \mathrm{hPa}$ and $100 \mathrm{hPa}$ for both initial conditions without (Fig. 4a) and with (Fig. 
4b) the TMI data. The figures indicate that assimilation of TMI data leads to notable increases of relative humidity and decreases of the divergences in the upper level atmosphere (Fig. $4 \mathrm{c}$ ).

\subsection{Bogus Vortex}

Since the initial conditions derived from the GEOS analyses contain a poor representation of the hurricane vortex, additional numerical experiments are conducted in which a bogus vortex is introduced into the initial conditions.

It has been shown that a reasonable bogus vortex is helpful for hurricane tropical cyclone simulations (Kurihara 1993; Leslie et al. 1995). Zou and Xiao (2000) proposed a bogus vortex technique that assimilates bogus vortex information using 4-D VAR. The method requires two steps: 1) Specification of a bogus vortex by defining the position, radius of maximum surface wind (RMW) and minimum SLP of the initial vortex, and prescribing a symmetric SLP distribution over the vortex region; 2) assuming that the time tendency of SLP is small in a short time period and then assimilating the specified bogus SLP field into the numerical model within a 30-minute assimilation window. They demonstrated the capability of this technique by using the MM5 adjoint system (Zou et al. 1997). Pu and Braun (2000) recently modified this technique to include bogus wind information because they found that the wind information was required to ensure gradient wind balance, which helps to produce a better vortex structure and prevent vortex spindown problems. In this study, the vortex technique of $\mathrm{Pu}$ and Braun (2000) is used to generate the bogus vortex, with assimilation of the bogus vortex information is applied only to the $45-\mathrm{km}$ domain. Based upon the best available estimates, the parameters 
defining the bogus vortex are the follows: storm centeral pressure $\mathrm{p}_{\mathrm{c}}=955 \mathrm{hPa}$ at the typhoon center $\left(7.6^{\circ} \mathrm{N}, 166.5^{\circ} \mathrm{E}\right)$, an environmental pressure of $\mathrm{p}_{\mathrm{n}}=1012 \mathrm{hPa}$, maximum surface wind $V_{m}=51.4 \mathrm{~ms}^{-1}$ and radius of maximum wind (RMW) $R_{m}=135 \mathrm{~km}$. A large RMW is used because the $45-\mathrm{km}$ grid spacing is inadequate for resolving the eye for realistic vortex of $R_{m}$. The bogus information extends out to a radius of $350 \mathrm{~km}$ for both SLP and gradient winds. The initial conditions derived from 12-h GEOS analyses with TMI rainfall, as described in the previous section, are taken as the first guess fields for the 4-D VAR system. Thus, the TMI rainfall information and mesosale bogus vortex data are incorporated together in the initial conditions. After assimilation of the bogus vortex, the 15-km nested domain is initialized by interpolation (see Grell et al. 1995) of all prognostic variables from the $45-\mathrm{km}$ mesh.

Figure 5 shows the SLP field and wind vectors and divergence at $850 \mathrm{hPa}$ after the bogus vortex assimilation for the $15-\mathrm{km}$ domain. As expected, a strong vortex has been successfully introduced into the mesoscale initial fields. The intensity of the bogus vortex is close to the estimated intensity of Typhoon Paka. The vortex structure also extends throughout the troposphere. Figure 6 compares vertical cross sections of potential temperature and wind speed through the typhoon center before and after bogus data assimilation, showing that the temperature and wind structure are much improved with inclusion of the bogus vortex. A realistic wind structure and strong warm core feature near the typhoon center are well resolved in the initial conditions.

\section{Simulation results}

The numerical simulation of Paka is conducted for $72-\mathrm{h}$. Figure 7 compares the simulated tracks with the observed track for Paka. Results show that inclusion of the 
TMI data in the initial conditions slows the speed of the storm movement and improves the storm track (Table 3). However, this positive improvement does not change the direction of movement of the storm so that the track errors still remain large. The bogus vortex (BGS) result in significant improvement of the track forecast for Paka, partly because it improves the initial location of the vortex, and also because improves the interaction of the vortex with the environmental flow.

Figure 8 shows the temporal variation of maximum winds at the lowest model level (Fig.8a) and the minimum SLP (or typhoon central pressure, Fig. 8b). The winds are compared with the maximum surface wind estimation (courtesy of archives from Unisys Corporation on http://weather.unisys.com/hurricane/index.html). There is no observed SLP estimation available for this comparison. The Fig. 8a show substantial improvement of the maximum wind forecast when the model is started from the initial analysis with the TMI data. Although the differences between the "GEOS0" and "GEOSTRMM" are quite small at the initial time, significant differences develop after $6 \mathrm{~h}$ and even greater differences occur after $36 \mathrm{~h}$ as the storm in experiment "GEOSTRMM" becomes a typhoon and intensifies rapidly. The storm in the experiment "GEOSO" undergoes much slower intensification and remains a tropical storm until 60-h. The numerical simulation with the bogus vortex provides a much better forecast in terms of both maximum wind and minimum SLP, comparing well with the estimated maximum wind information (Fig.8a).

Figure 9 compares with the satellite picture of SSM/I brightness temperature from 85 GHz channel at 0911 UTC 13 December 1997 (Fig.9a) with the forecasted 1-h accumulated precipitation at $33 \mathrm{~h}$ (corresponding to 0900 UTC 13 December 1997) from 
the 5-km grid for experiments "GEOS0" (Fig.9b), "GEOSTRMM" (Fig.9c) and "BGS" (Fig.9d). At the time, Paka was a mature typhoon with a maximum surface wind of about $53 \mathrm{~ms}^{-1}$. Significant differences among the rainfall forecasts are seen between the three experiments. Without assimilation of TMI rainfall data (GEOS0), the simulation produces only marginal pressure deepening with scattered rainfall on the eastern side of the low-pressure system. With assimilation of the TMI rainfall (GEOSTRMM), the simulation produces a much more organized outer precipitation structure and a relatively strong tropical cyclone. The rainfall pattern reproduces the major features of the satellite observed strong convective pattern, but an organized eyewall structure is generally lacking. With both TMI rainfall and the bogus vortex (BGS), the simulation produces the precipitation features that are consistent with the major observed features, including a well-depended eyewall but fails to produce a weak rain band on the western side of the storm.

Figure 10 shows a similar comparison of the rainfall fields, but for the $57-\mathrm{h}$ forecast. At this time, experiment "GEOSTRMM" (Fig. 10c) reproduces a mature typhoon with central SLP of $974 \mathrm{hPa}$ and maximum surface winds of $45 \mathrm{~ms}^{-1}$. The rainfall pattern matches that observed by SSM/I (Fig. 10a), showing the heavy precipitation on the western side of the typhoon eye. Similar features are also observed in experiment "BGS" (Fig.10d) except that the intensity of the storm is even stronger. Without the TMI data included in the initial conditions, experiment "GEOS0" remains a tropical storm and the precipitation field only shows relatively organized rain bands on the eastern side of the storm (Fig. 10b). 
Figure 11 compares the vertical structure of temperature and tangential wind speed field within zonally oriented cross sections through the storm center at 57-h. Similar structural features are found in experiments "GEOSTRMM" and "BGS", as they both resolve strong tangential circulation and the warm core feature in the eye very well. On the other hand, experiment GEOS0 shows a significantly weaker feature. Although the wind speeds show a weak maximum near the center of the storm, indicating a weak eye wall structure, the overall intensity of the wind speed is much too weak. Only a very weak warm temperature anomaly appears in the lower troposphere.

Since the simulation results with bogus vortex show significant improvement in the Paka's forecast, as a further comparison, an additional experiment (BGS0) is also conducted in which a bogus vortex, with the same vortex parameters as in experiment BGS, was introduced into the GEOS analysis without assimilation of TMI data. Numerical simulation results with experiment BGS0 show very similar forecast impacts as that in experiment BGS, with storm track and intensity forecasts are improved significantly (Fig. 7 and 8). Only slight differences are observed between the both experiments. These results might suggest that the bogus vortex can play a dominant role in the forecasts of the mature typhoons in terms of their intensity and track. However, since the rainfall data are originally assimilated into a global model with coarse resolution in this study, it should be necessary to confirm this conclusion in a future study, provided the rainfall data are directly assimilated into the mesoscale model. On the other hand, as we noted in the figures, the track forecasts in the experiment BGS0 are slight worse than the forecasts in experiment BGS most of the times. Furthermore, distinguishable differences are also observed in the precipitation structure between two 
experiments during the first $36 \mathrm{~h}$ forecast. For instance, Figure 12 shows the $1 \mathrm{~h}$ accumulated precipitation at $33 \mathrm{~h}$ from experiment BGS0, corresponding to the results in Figure 9. Comparing two sets of simulations (Fig. 12 and Fig. 9d) with SSM/I observations (Fig. 9a), we found that the experiment BGS produces a more realistic precipitation structure, which is more consistent with the SSM/T observations. The better precipitation structure in BGS is certainly attributed to the impact of including the TMI rainfall data in the initial and boundary conditions. The results might also suggest that, although the initial vortex can play a dominant role in the forecasts of a matured typhoon, assimilation of rainfall data still brings some additional benefits to the forecast, especially to the forecast of short-term precipitation.

\section{Summary and Discussion}

Several numerical simulations have been conducted in order to examine the impact of assimilated rainfall data on forecast of tropical cyclone structure and intensity. Results show significant differences among the first three experiments with initial conditions derived from: 1) GEOS analysis without assimilation of TMI rainfall, 2) GEOS analysis with assimilation of TMI rainfall data and 3) Similar to 1) and 2) but also including mesoscale bogus vortices assimilated into the analysis using 4-D VAR technique. The numerical results show that:

- Assimilation of TMI rainfall data into GEOS global analysis results the stronger lower level confluences and deeper initial SLP of the storm. It also causes the increases of the moisture and divergences in upper level atmosphere and the decreases of the divergences in the lower level atmosphere, and therefore lead to 
the improvement of the environmental condition that storm evolutes. As the consequent, the storm forecast is improved significantly with the case GEOSTRMM in terms of typhoon structure and intensity. Since the GEOS largescale analysis does not contain any mesoscale vortex information, experiment GEOSTRMM reproduces a storm of typhoon intensity after $36 \mathrm{~h}$ forecast, while experiment GEOSO requires $60 \mathrm{~h}$ of forecast to generate a typhoon.

- Further forecast improvements are obtained by combining the TMI rainfall data with other information, such as a bogus vortex in the initial condition. As shown in experiment "BGS", a bogus vortex that replicates the real intensity of the storm can be introduced into the initial conditions. The numerical simulation reproduces a very reasonable typhoon track, intensity, and precipitation structure.

- The bogus vortex can play a dominant role in forecasts of the intensity of mature typhoons. However, assimilation of rainfall data into the model still contributes additional beneficial impacts, for instance, it helps to produce a more realistic short-term precipitation forecast.

More detail evaluation of TRMM data impact and directly assimilating the TMI rainfall into the mesoscale model by 4-D VAR is in progress. Results will be reported in the near future.

\section{Acknowledgements}

This work is supported by the NASA Headquarters Atmospheric Dynamics and Thermodynamics Program, and by the NASA TRMM project. The authors are grateful to 
Dr. R. Kakar (NASA/HQ) for his support of this research. Acknowledgement is also made to NASA/Goddard Space Flight Center for computer time used in this research. 


\section{References:}

Bloom, S. C., L. L. Takacs, A. M. da Silva, and D. V. Ledvina, 1996: Data assimilation using increamental analysis updates. Mon. Wea. Rev., 124, 1256-1271.

Dudhia, J., 1993: A nonhydrostatic version of the Penn State-NCAR mesoscale model: Validation tests and simulation of an Atlantic cyclone and cold front. Mon. Wea. Rev., 121, 1493-1513

Grell, G. A., J. Dudhia, and D. R. Stauffer, 1995: A description of the fifth-generation Penn State/ NCAR mesoscale model (MM5). NCAR Technical Note, NCAR/TN$398+$ STR, 138 pp. [Available from NCAR Publications Office, P. O. Box 3000, Boulder, CO 80307-3000].

Hou, A. Y., S. Q. Zhang, A. M. da Silva, W. S. Olson, 2001:Improving assimilated global datasets using TMI rainfall and columnar moisture observations. J. of Climate, 13, 4180-4195.

Krishnamurti, T. N., H. S. Bedi, and K. Ingles, 1993: Physical initialization using SSM/I rain rates. Tellus, $\mathbf{4 5 A}, 247-269$.

Kummerow, C. , W. S. Olson, and L. Giglio, 1996: A simplified scheme for obtaining precipitation and vertical hydrometeor profile from passive microwave sensor. IEEE Trans. Geosci. Remote Sens., 34, 1213-1232.

Kurihara, Y., M. A. Bender, and R. J. Ross, 1993: An initialization scheme of hurricane models by vortex specification. Mon. Wea. Rev., 121, 2030-2045.

Leslie, L. M., and G. J. Holland, 1995: On the bogussing of tropical cyclones in numerical models: A comparison of vortex profiles. Meteorol. Atmos. Phys., $56,101-110$.

Manning, K. W., and P. L. Haagenson, 1992: Data ingest and objective analysis for the PSU/NCAR modeling system: Programs DATAGRID and RAWINS. NCAR Technical Note (NCAR/TN-376+IA), 209 pp. [Available from NCAR Publications Office, P. O. Box 3000, Boulder, CO 80307-3000]

Olson, W. S., C. D. Kummerow, G. M. Heymsfield, and L. Giglio, 1996: A method for combined passive-active microwave retrievals of cloud and precipitation profiles. $J$. Appl. Meteor., 35, 1763-1789. 
Olson, W. S., C. D. Kummerow, Y. Hong, and W.-K. Tao, 1999: Atmospheric latent heating distributions in the Tropics derived from passive microwave radiometer measurements. J. Appl. Meteor., 38, 633-664.

Pu, Z.-X., S. A. Braun 2001: Evaluation of bogus vortex techniques with fourdimensional variational data assimilation. Mon. Wea. Rev. (in press).

Rodgers, E., W. Olson, J. Halverson, J. Simpson, H. Pierce, 2000: Environmental forcing of super typhoon Paka's (1997) latent heat structure. Mon. Wea. Rev., 39,1983-2006.

Smolarkiewicz, P. K., and G. A. Grell, 1992: A class of monotone interpolation schemes. J. Comp. Phys., 101, 431-440.

Tao, W.-K., and J. Simpson, 1993: Goddard cumulus ensemble model. Part I: Model description. Terrest. Atmos. Oceanic Sci., 4, 35-72.

Wang, Y., W.-K. Tao, J. Simpson, S. Lang, 2001: The sensitivity of tropical squall lines to surface fluxes: Cloud resolving model simulations. Q. J. R. Meteor. Soc. (conditionally accepted)

Zhang, D.-L., and R. A. Anthes, 1982: A high-resolution model of the planetary boundary layer — Sensitivity tests and comparisons with SESAME-79 data. J. Appl. Meteor., 21, 1594-1609.

Zou, X. and Q. Xiao, 2000: Studies on the initialization and simulation of a mature hurricane using a variational bogus data assimilation scheme. J. Atmos. Sci., 57, 836860

Zou, X., W. Huang and Q. Xiao, 1998: A user's guide to the MM5 adjoint modeling system. NCAR TN-437+IA. MMM division, NCAR. [Available from NCAR Publications Office, P. O. Box 3000, Boulder, CO 80307-3000].

Zupanski, D. and F. Mesinger, 1995: Four-dimensional variational assimilation of precipitation data. Mon. Wea. Rev., 123, 1112-1127. 


\section{Figure Caption:}

Figure 1. Paka's intensity (dashed line, $\mathrm{ms}^{-1}$ ) and SSM/I (open circle) and TMI-derived (x) mean total (i.e., combined stratified and convectively generated rain rates) inner-core (within $111 \mathrm{~km}$ of the center) rain rates (solid line, $\mathrm{mm} \mathrm{h}^{-1}$ ) for the period between 9 and $21 \mathrm{Dec} 1997$.

Figure 2. Location of the model domains for simulation of Super Typhoon Paka (1997).

Domain A is the $135-\mathrm{km}$ grid and domain B is the nested, $45-\mathrm{km}$ grid and domain $\mathrm{C}$ is the $15-\mathrm{km}$ grid used in the forecast. Domain is the $5-\mathrm{km}$ grid and it is started from 24-h forecast. Domain D moves with the storm center (the domain location may vary in different experiment). For experiment "GEOSTRMM", domain D move from $D_{1}$ to $\mathrm{D}_{2}$ during 24 to 60 -hour forecast.

Figure 3a. Distributions of the initial sea-level pressure (contour interval, $2 \mathrm{hPa}$ ), horizontal wind vectors and divergence field (the shaded contour only show the divergence less than $-0.000007 \mathrm{~s}^{-1}$ ) at $850 \mathrm{hPa}$ in a part of $15-\mathrm{km}$ domain, for the initial conditions in experiment GEOSO (a), experiment GEOSTRMM (b), and the differences of all above fields between GEOSTRMM and GEOSO (c).

Figure 4. The initial divergence (contour interval $2 \times 10^{-5} \mathrm{~s}^{-1}$ ) at $150 \mathrm{hPa}$ and averaged relative humidity (shaded contour, \%) between level $500 \mathrm{hPa}$ to $100 \mathrm{hPa}$ for a) GEOSO, b) GEOSTRMM and c) the differences between GEOSTRMM and GEOSO. The sign " $\mathbf{X}$ " denotes the position of the interested circulation center near the surface.

Figure 5. Same as Figure 3a, but for initial condition in experiment "BGS" with the contour interval for SLP $8 \mathrm{hPa}$.

Figure 6. East-west cross sections of initial potential temperature field ( $4 \mathrm{~K}$ interval) and wind speed $\left(5 \mathrm{~ms}^{-1}\right.$ interval) through the center of storms (corresponding to the centers in Fig.3b and Fig.5) for experiments a) GEOSTRMM and b) BGS.

Figure 7. Forecasts of the track for all experiments compared to the observed track. Center locations along the tracks are indicated every 6 hours.

Figure 8. Time series (at 6-hour intervals) of a) maximum winds $\left(\mathrm{m} \mathrm{s}^{-1}\right.$ ) at the lowest model level $(\sigma=0.995$, approximately $50 \mathrm{~m}$ ) and b) minimum sea-level pressure $(\mathrm{hPa})$. The results during $24 \mathrm{~h}-60 \mathrm{~h}$ are the forecasts at $5-\mathrm{km}$ grid spacing.

Figure 9. Comparison of the satellite picture of SSM/I brightness temperature at $85 \mathrm{GHz}$ Channel at 0911 UTC 13 December 1997 (a) with the forecasted $1 \mathrm{~h}$ accumulated precipitation accumulation (contour started from $1 \mathrm{~mm} \mathrm{~h}^{-1}$ with interval of $10 \mathrm{~mm} \mathrm{~h}^{-1}$ ) at 33-h forecast (corresponding to 0900 UTC 13 December 1997) at 5km grid spacing, for experiments "GEOSO" (b), "GEOSTRMM" (c) and "BGS" (d). 
Figure 10. Same as Figure 10, except for SSM/I brightness temperature at 0835 UTC 14 December 1997 (a) and $1 \mathrm{~h}$ precipitation accumulation at 57-h forecasts (corresponding to 0900 UTC 14 December 1997).

Figure 11. East-west cross sections of the potential temperature field (4K interval) and wind speed $(5 \mathrm{~m} / \mathrm{s}$ interval) through the center of the storms (corresponding to the storm centers in Fig 10) at 57-h forecast for experiment a) GEOS0, b) GEOSTRMM and c) BGS.

Figure 12. Same as Fig. 9d, except the forecast from experiment BGS0. 


\section{Table Caption:}

Table 1. The model design.

\begin{tabular}{lcccc}
\hline Domain & Mesh A & Mesh B & Mesh C & Mesh D \\
\hline Dimensions & $72 \times 56$ & $118 \times 88$ & $202 \times 169$ & $202 \times 169$ \\
Area coverage $\left(\mathrm{km}^{2}\right)$ & $9720 \times 7560$ & $5310 \times 3960$ & $3030 \times 2535$ & $1010 \times 845$ \\
Grid size $(\mathrm{km})$ & 135 & 45 & 15 & 5 \\
Time step(s) & 360 & 120 & 40 & 13.3 \\
Integration hours & $00-72$ & $00-72$ & $00-72$ & $24-60$ \\
\hline
\end{tabular}

Table 2. Experimental design

\begin{tabular}{|c|c|c|}
\hline $\begin{array}{l}\text { Numerical } \\
\text { Experiments }\end{array}$ & Model initial condition & $\begin{array}{l}\text { Bogus } \\
\text { Vortex }\end{array}$ \\
\hline GEOSO & GEOS anlysis without TMI rainfall & No \\
\hline GEOSTRMM & GEOS analysis with TMI rainfall & No \\
\hline BGS & GEOS analysis with TMI and bogus vortex & Yes \\
\hline BGSO & GEOS analysis without TMI rainfall but with bogus vortex & Yes \\
\hline
\end{tabular}

Table 3. Time series of the 6-h forecasted track error $(\mathbf{k m})$

\begin{tabular}{llllllllllllll}
\hline Forecast Time (h) & 00 & 06 & 12 & 18 & 24 & 30 & 36 & 42 & 48 & 54 & 60 & 66 & 72
\end{tabular}

\begin{tabular}{l|rrrrrrrrrrrrrrr}
\hline $\begin{array}{c}\text { Track } \\
\text { Error }(\mathrm{km})\end{array}$ \\
$\begin{array}{l}\text { Numerical } \\
\text { Experiments }\end{array}$ \\
\hline GEOS0 & 53 & 288 & 307 & 231 & 247 & 284 & 280 & 309 & 264 & 320 & 336 & 352 & 325 \\
GEOSTRMM & 41 & 156 & 210 & 218 & 211 & 211 & 227 & 215 & 160 & 185 & 174 & 192 & 170 \\
BGS & 0 & 14 & 57 & 73 & 67 & 45 & 51 & 30 & 81 & 98 & 85 & 60 & 55 \\
BGS0 & 0 & 45 & 50 & 67 & 60 & 90 & 70 & 80 & 95 & 112 & 95 & 115 & 120 \\
\hline
\end{tabular}




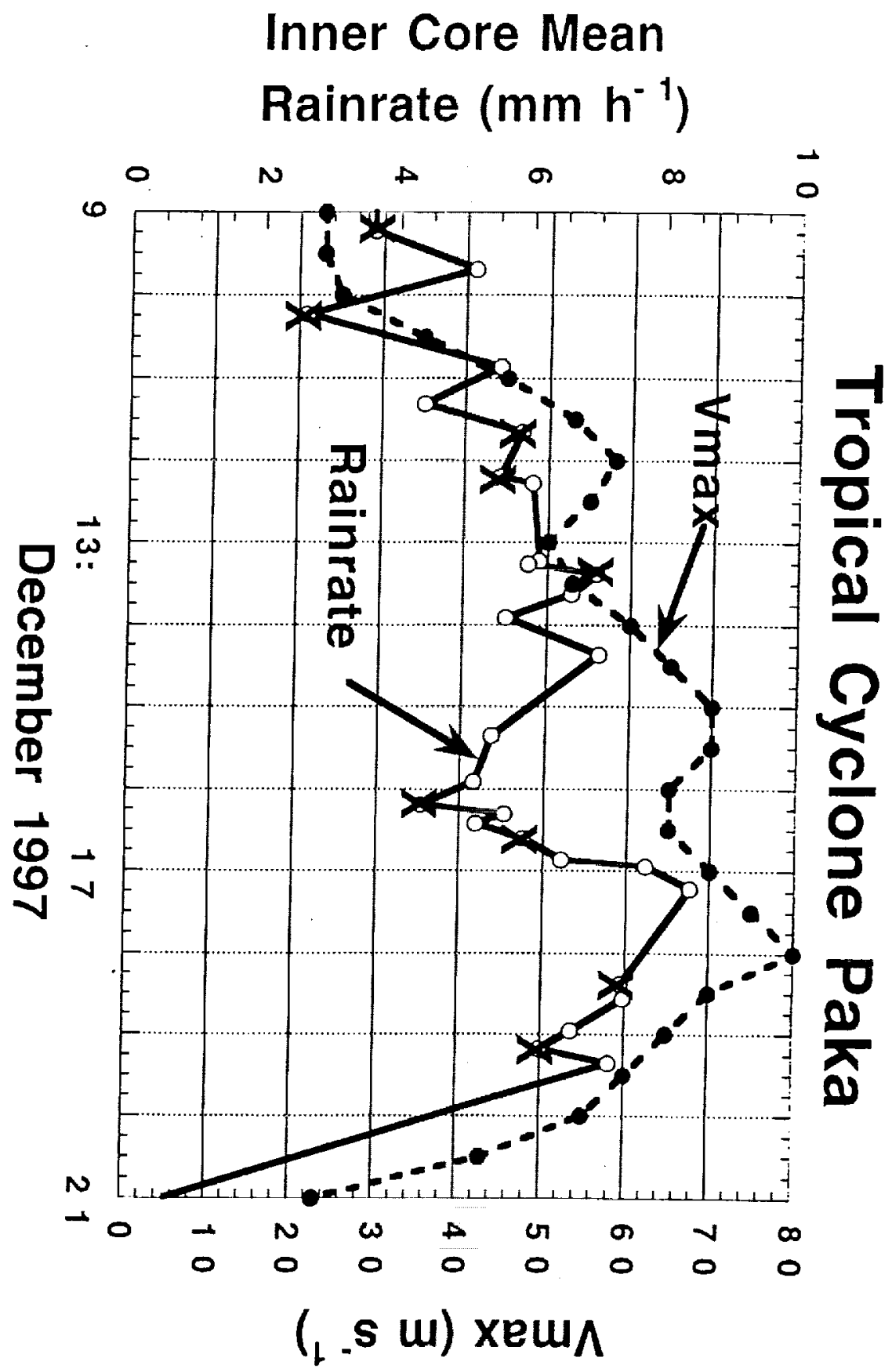




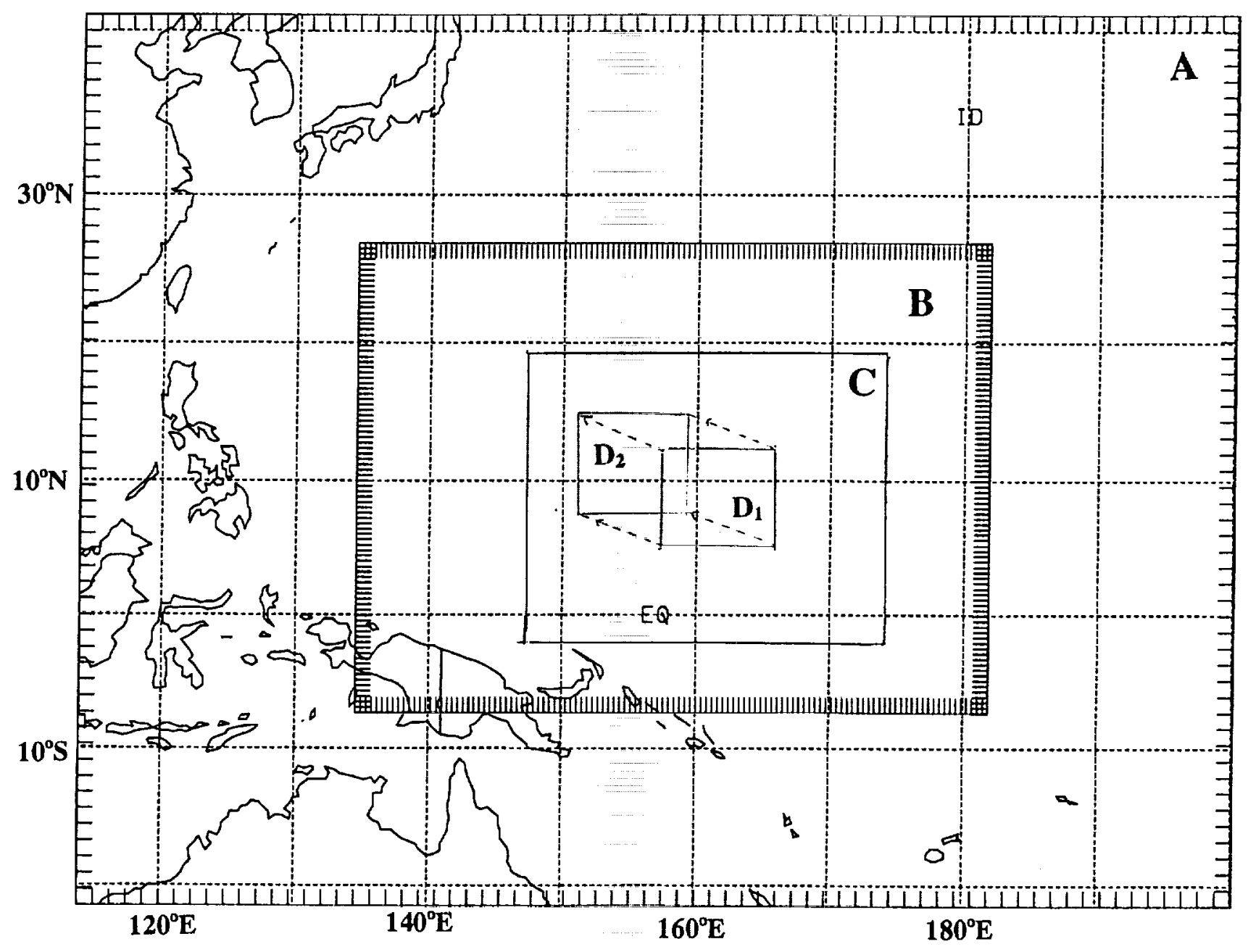

Fig. 2 
a)

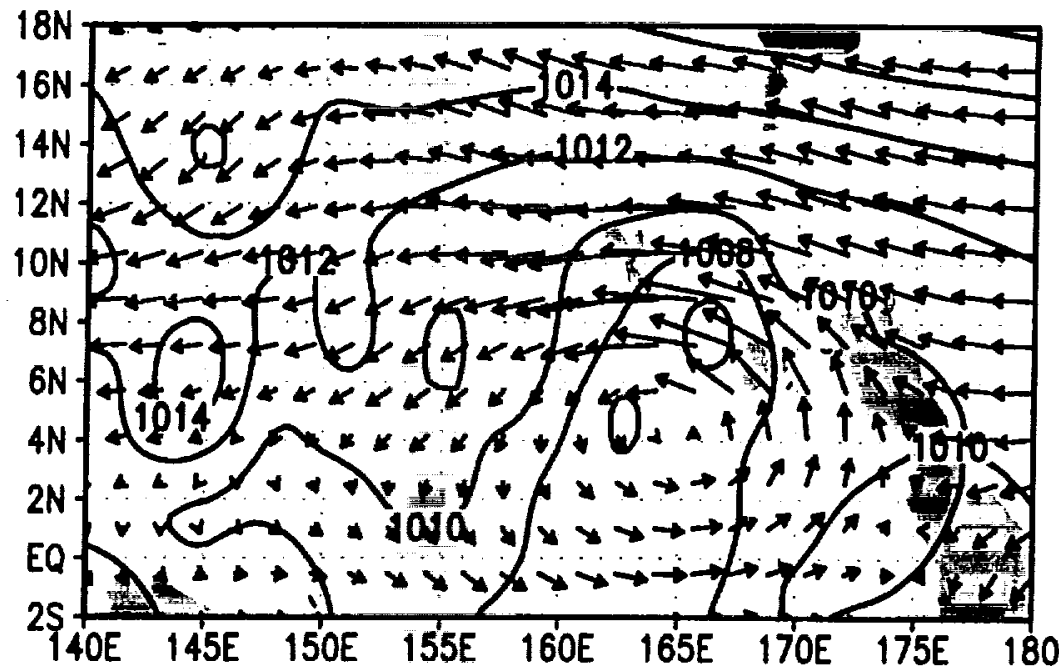

b)

GEOSTRMM

$\overrightarrow{20}$

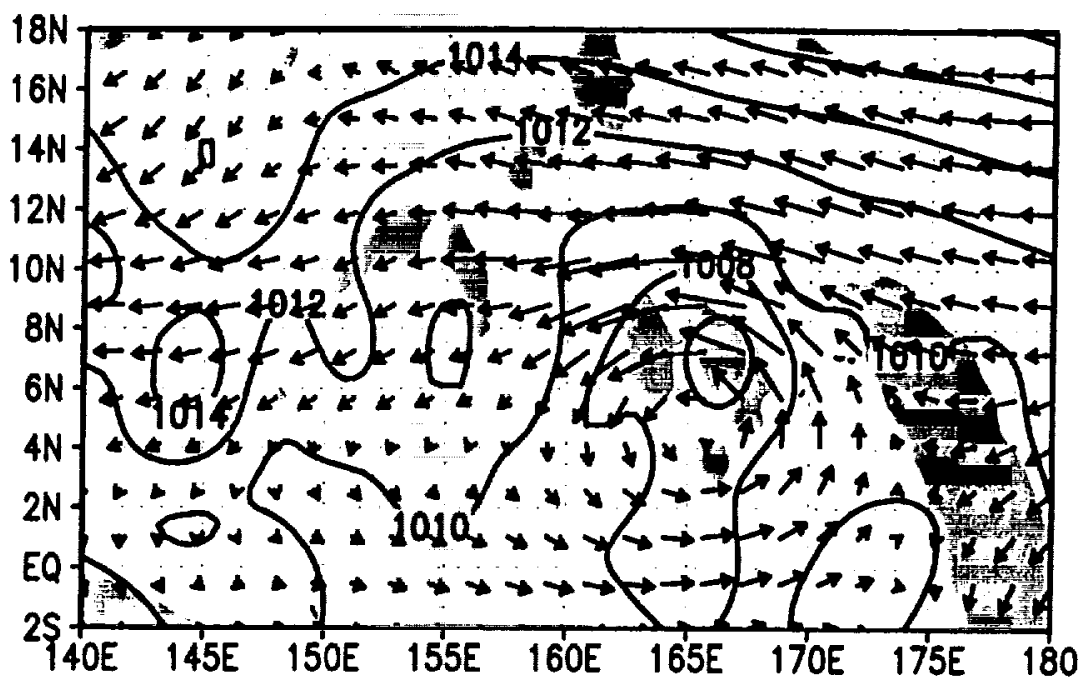

c) GEOSTRMM-GEOSO

$\overrightarrow{25}$

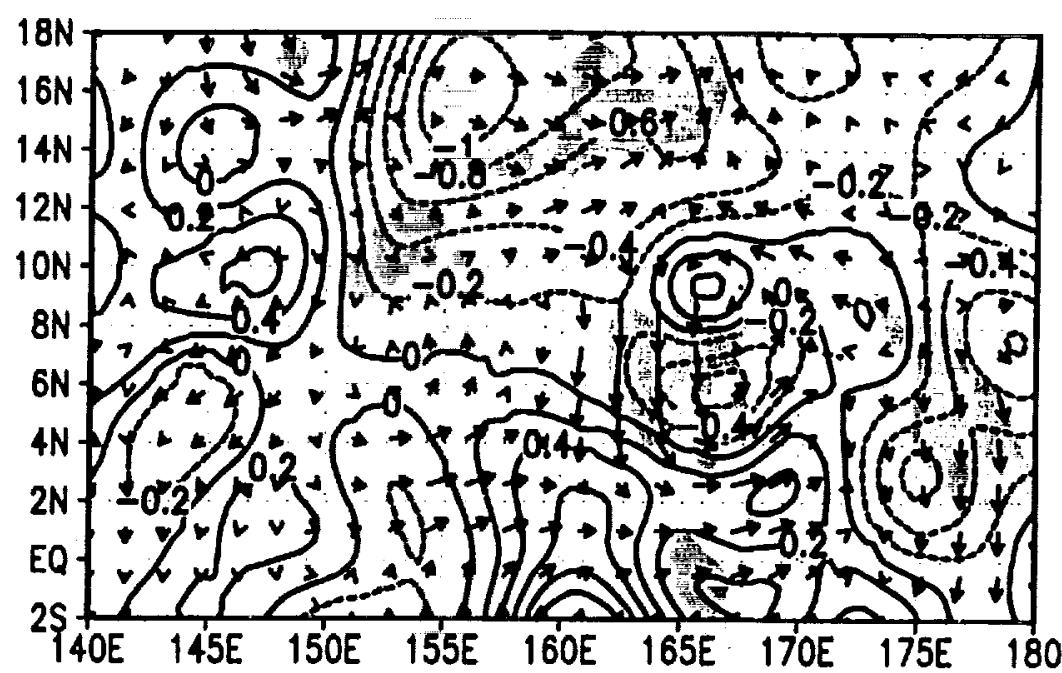


a)

\section{GEOSO}

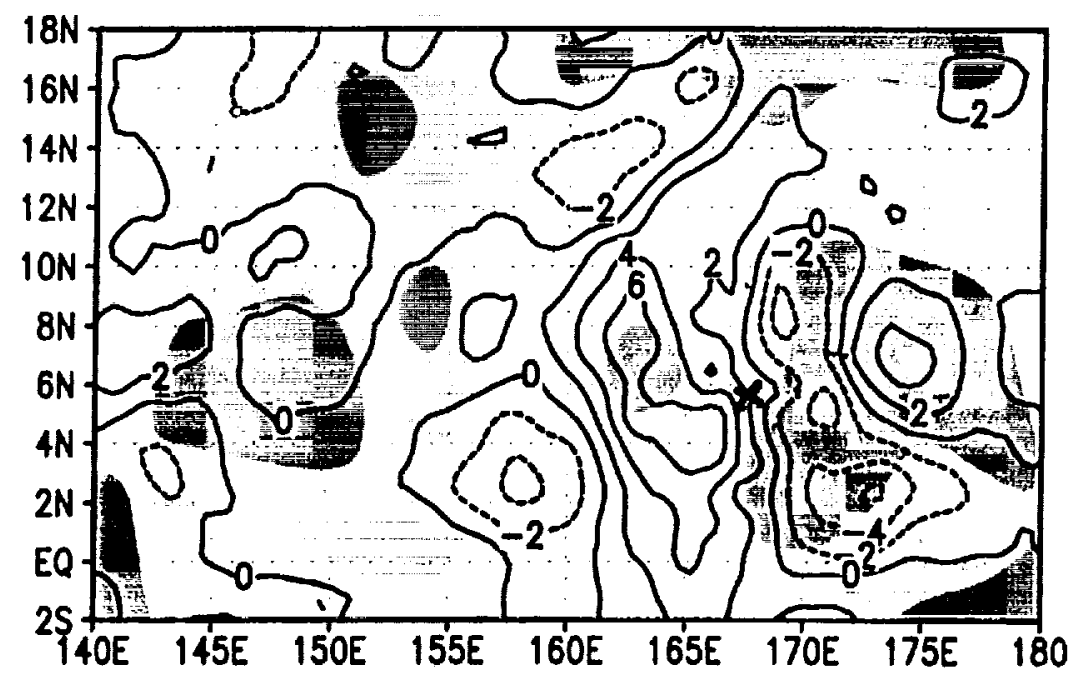

b)

GEOSTRMM

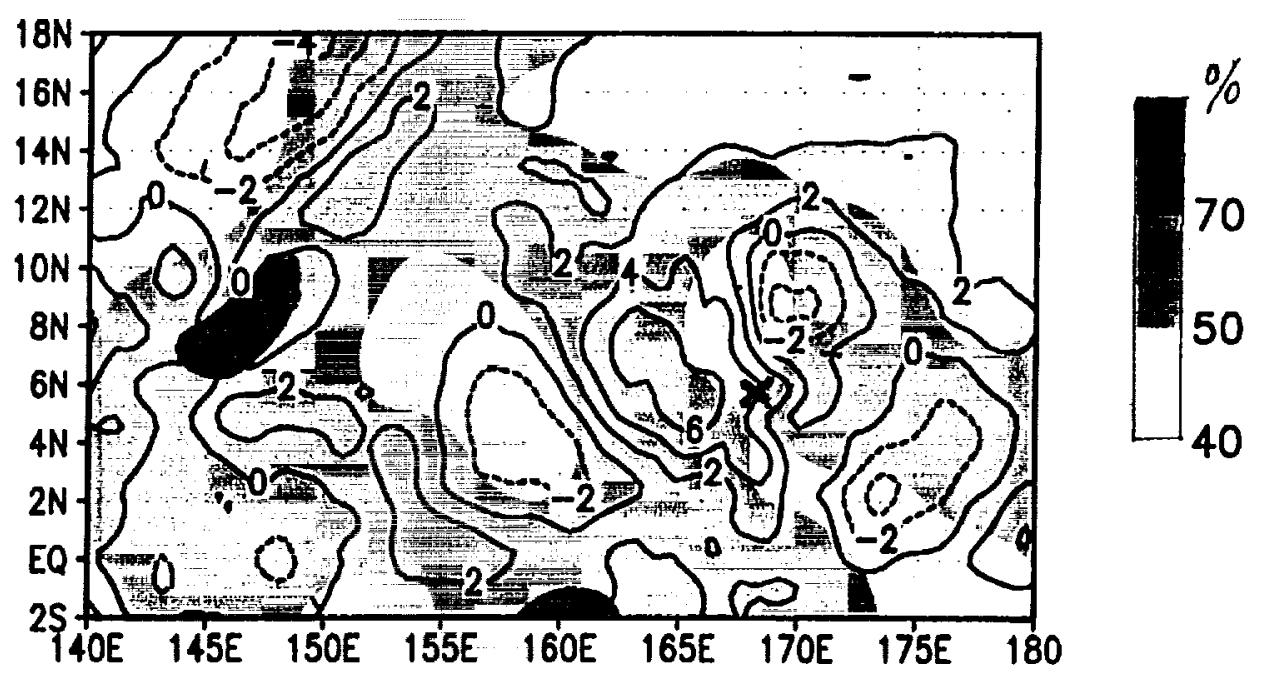

c)

GEOSTRMM-GEOSO

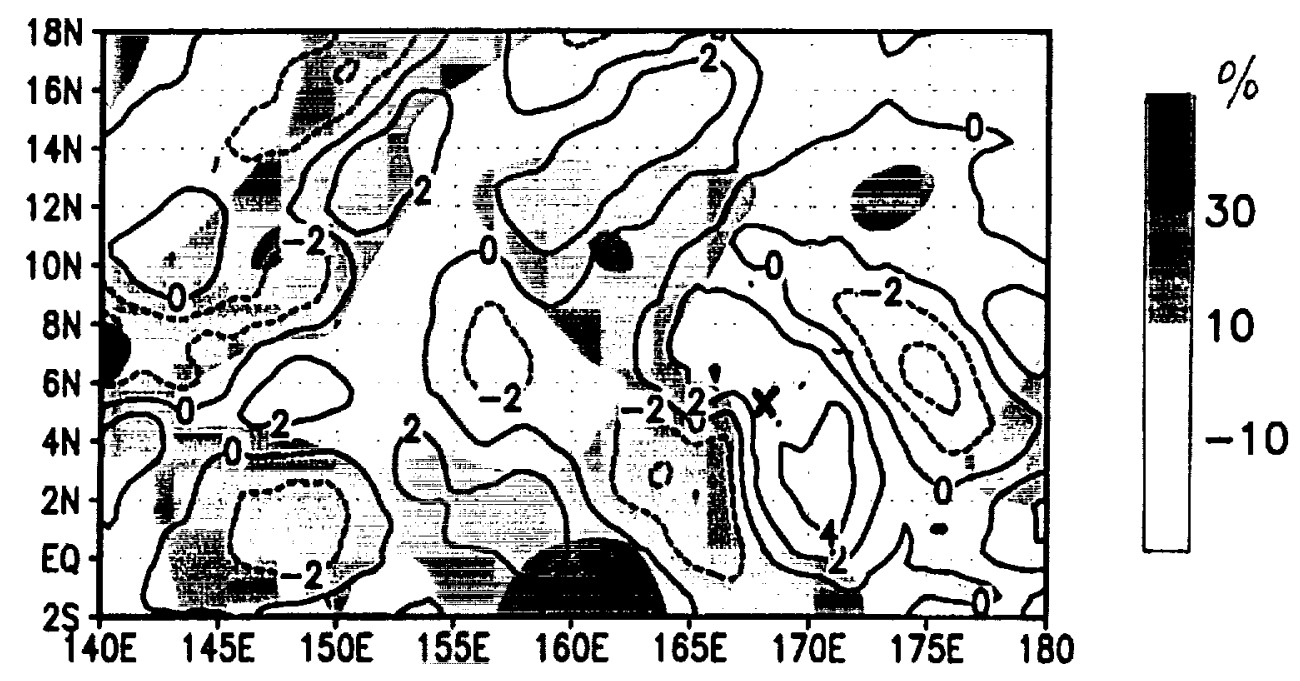




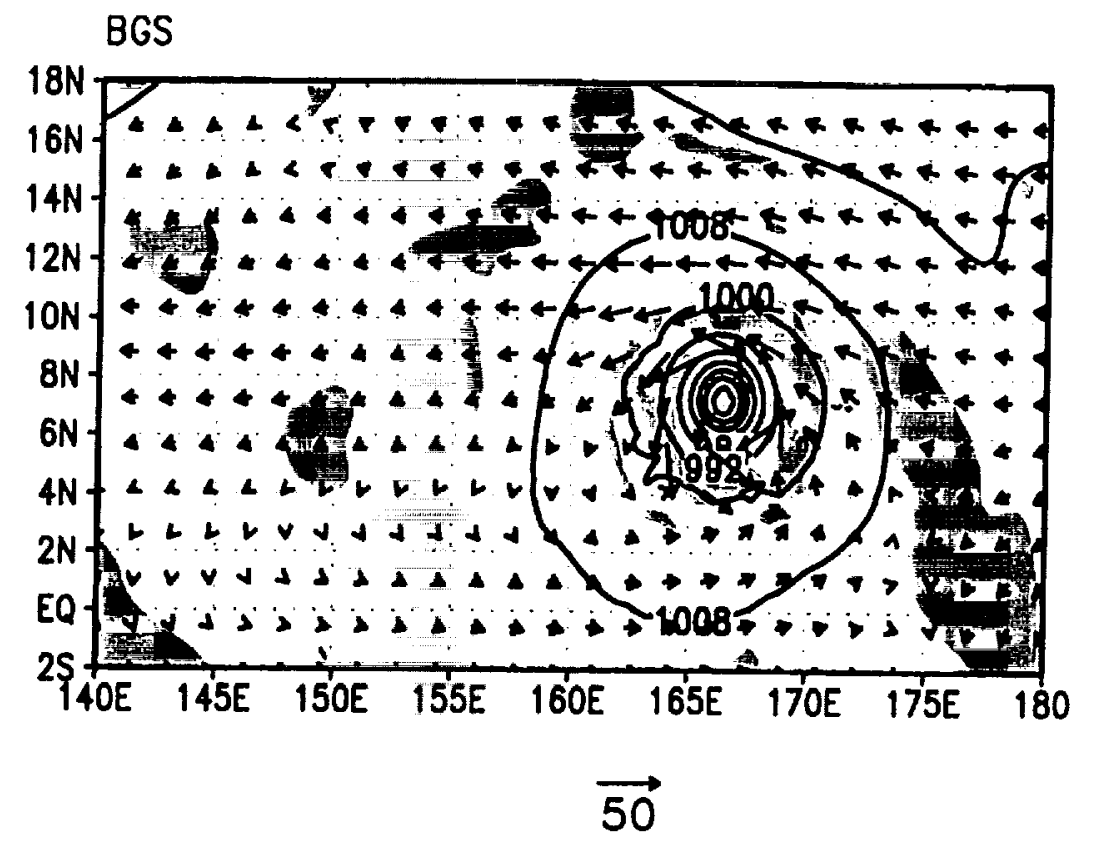

Fig. 5 

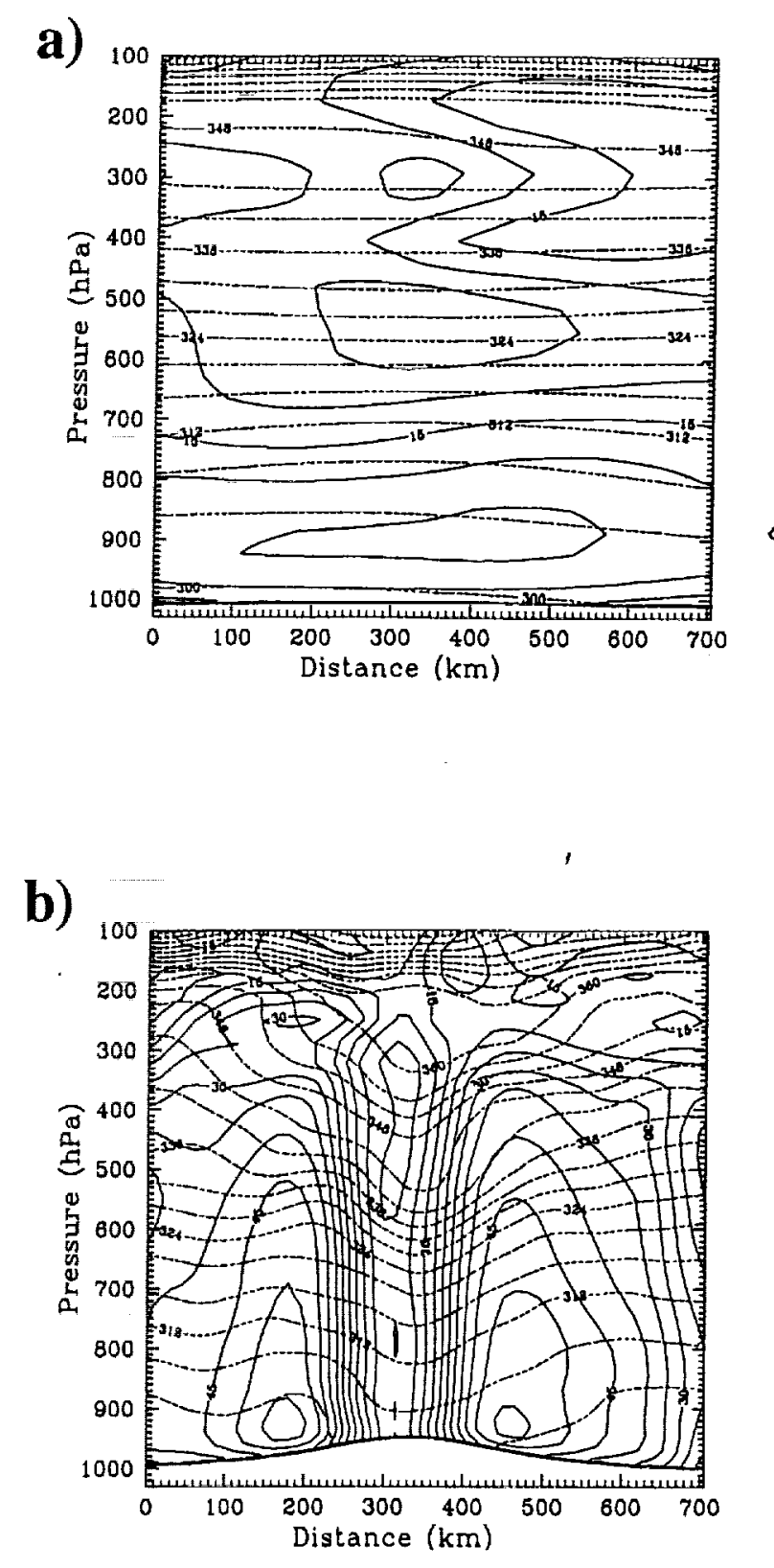

Fig. 6 


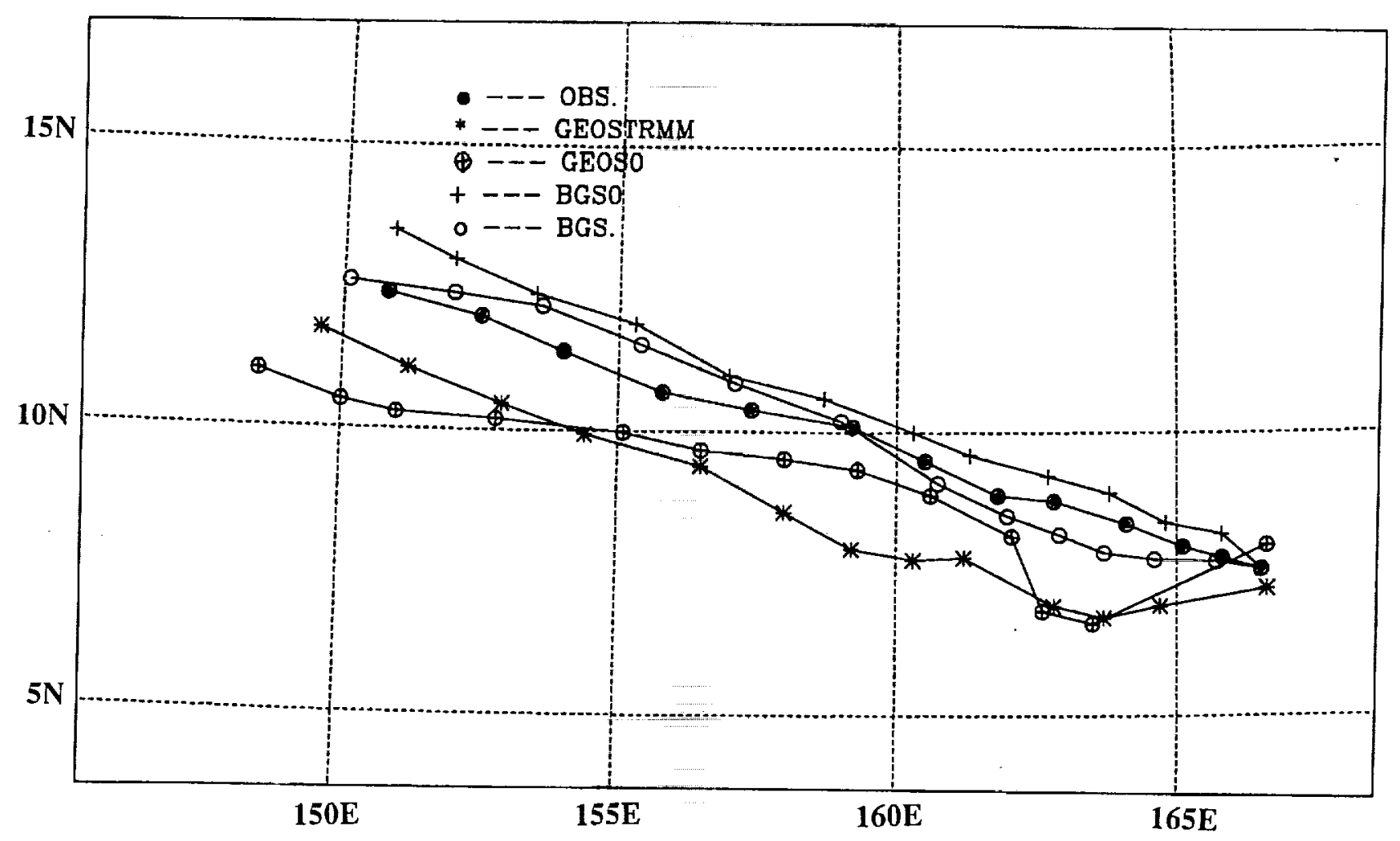

Fig. 7 

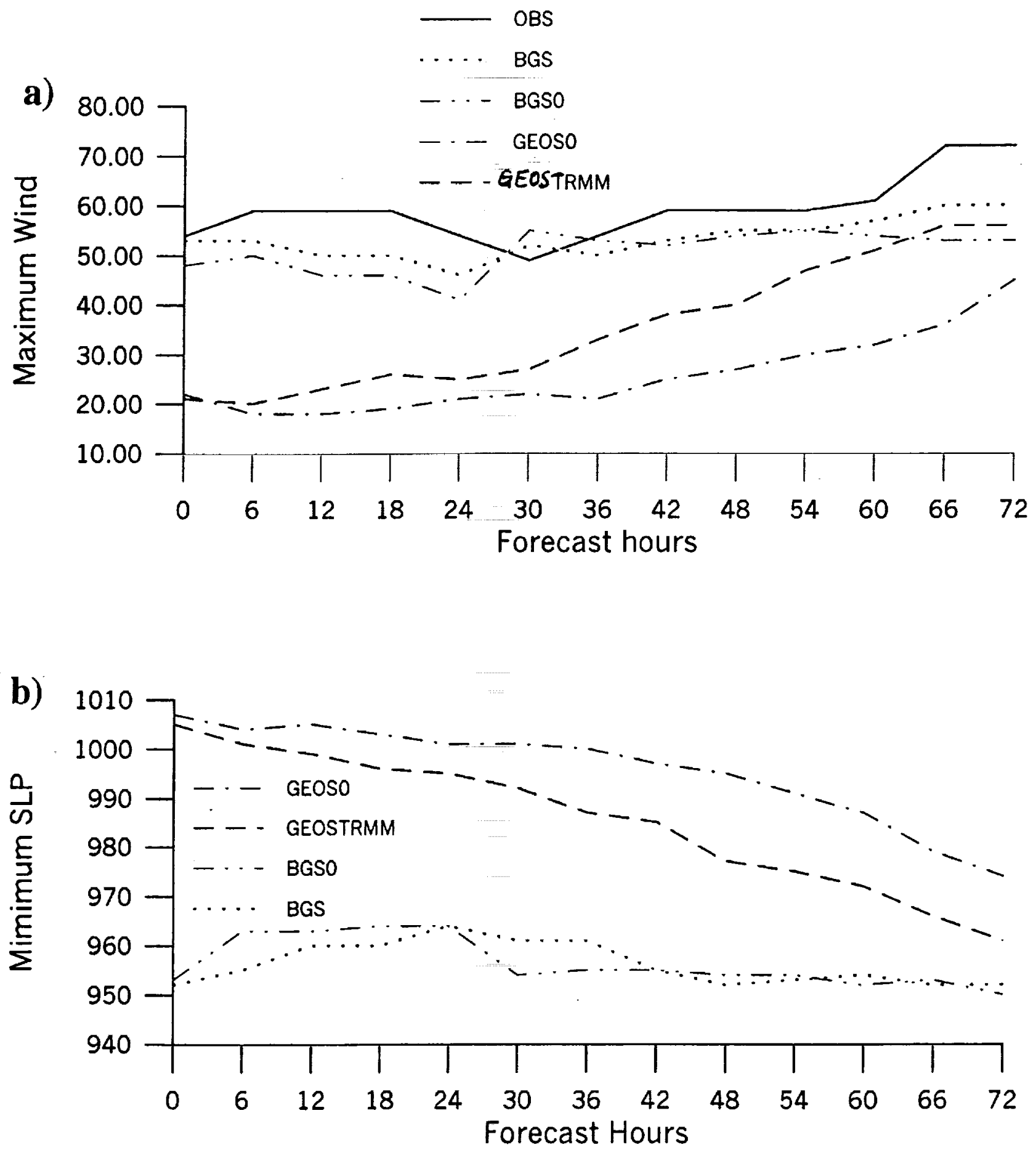

Fig. 8 

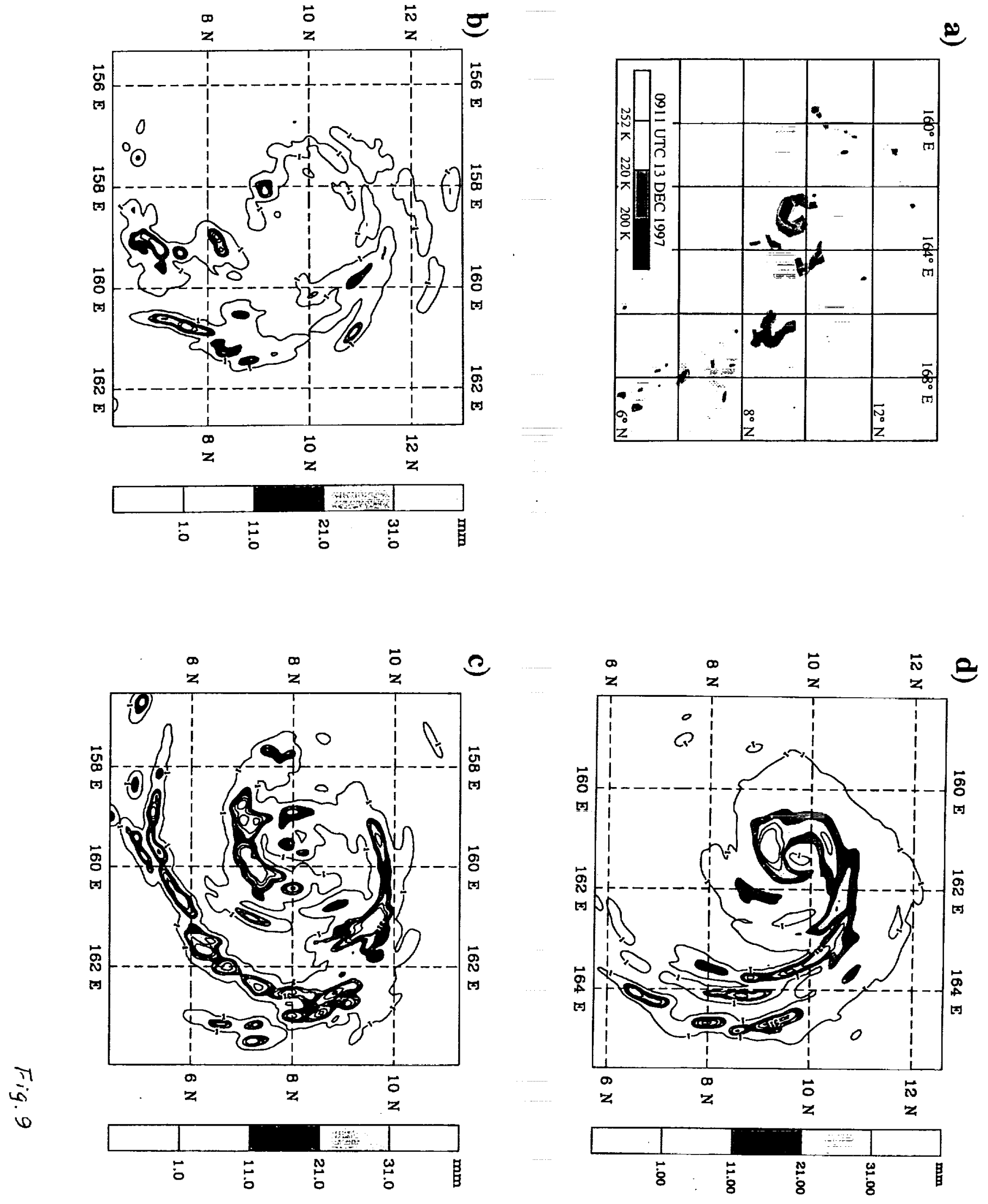

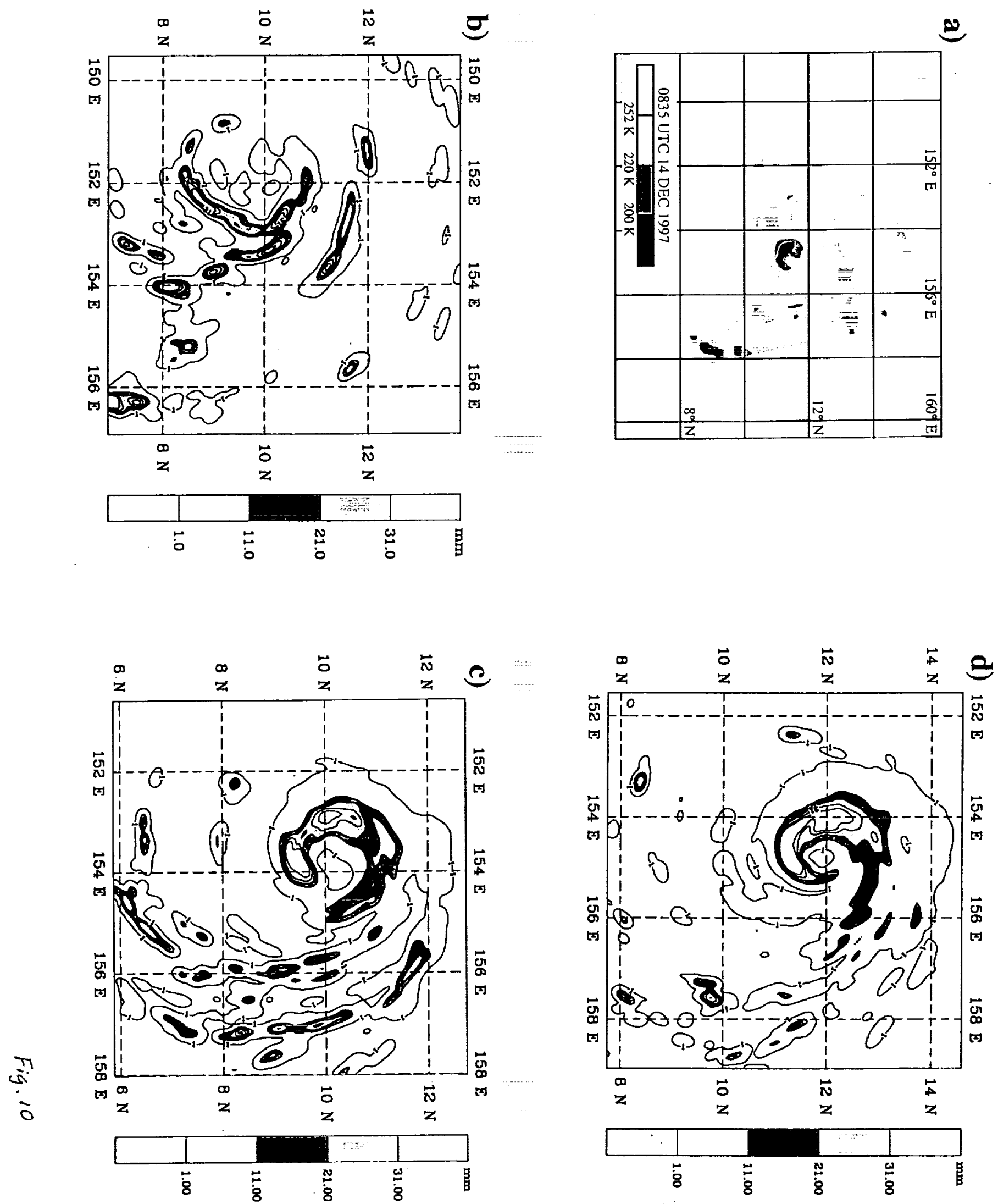


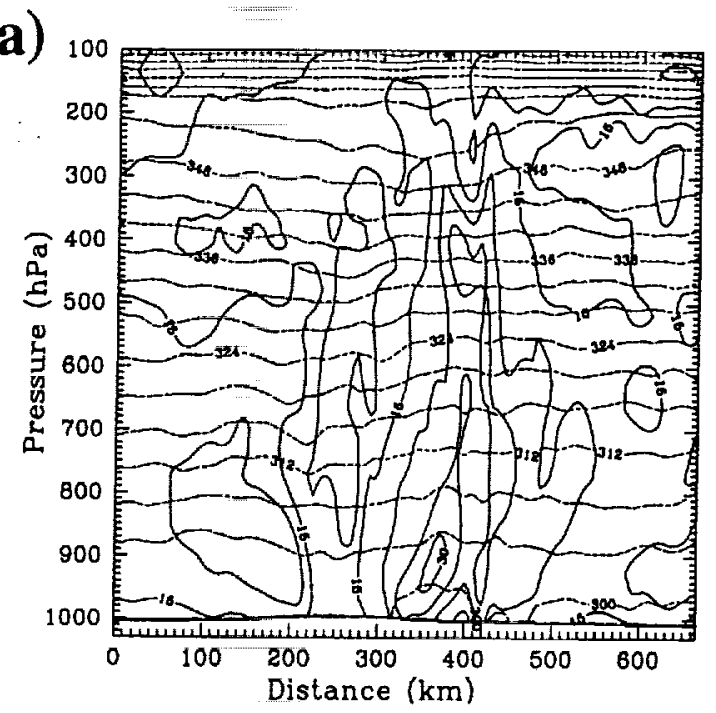

b)
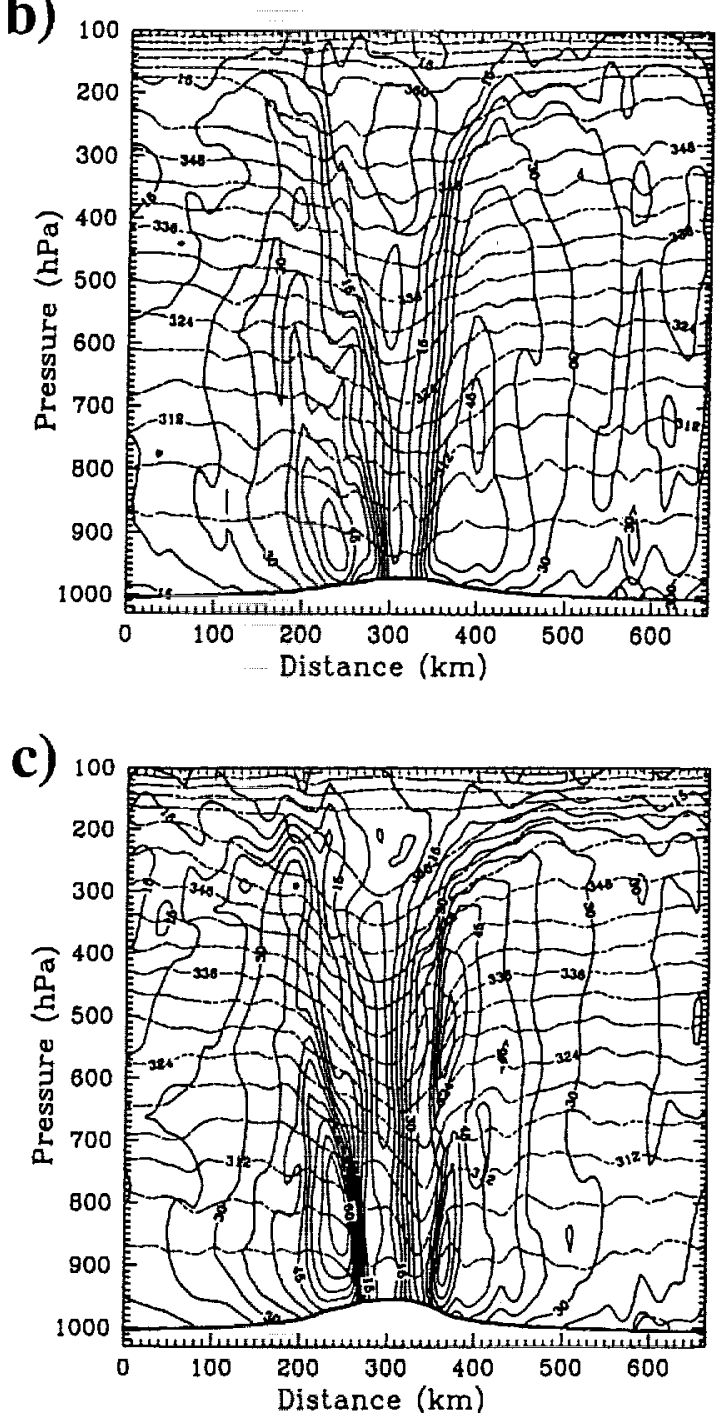

Fig. II 


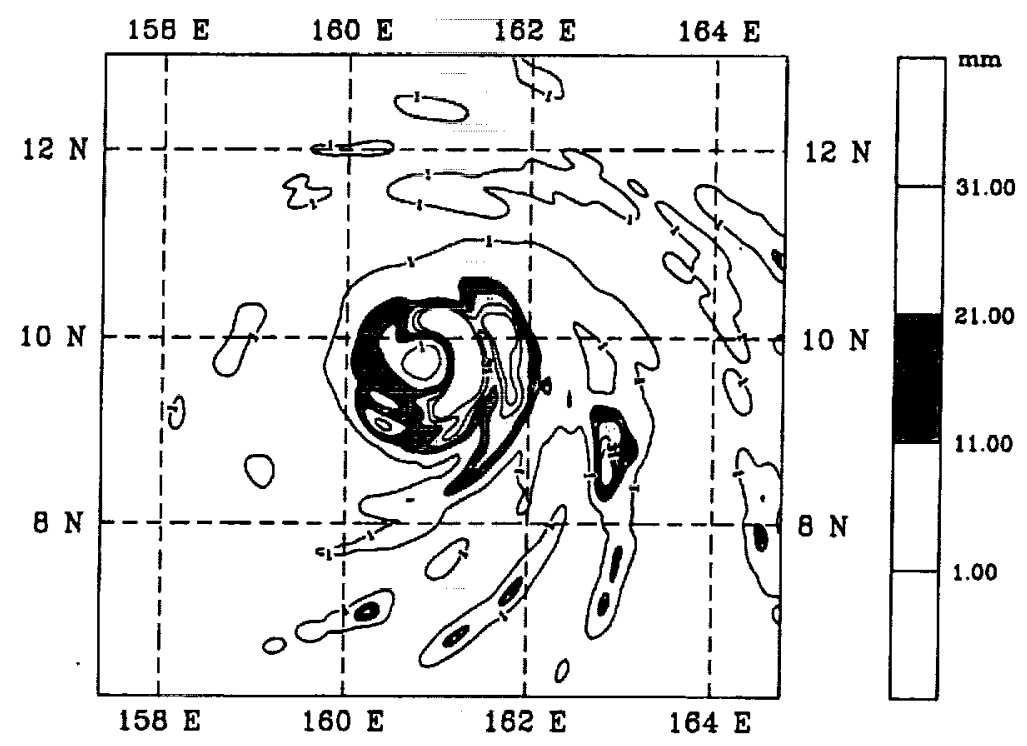

Fig. 12 